\title{
A EMERGÊNCIA DA UNIVERSIDADE OPERACIONAL: REDES, LIQUIDEZ E CAPITALISMO ACADÊMICO*
}

\author{
Tiago Fonseca Albuquerque Cavalcanti Sigahi $^{1}$ (D) \\ Patrícia Saltorato ${ }^{2}$ (D)
}

\begin{abstract}
RESUMO: Este artigo explora como novas formas de capital e de organização da vida humana têm contribuído para a construção de um cenário fértil para a consolidação de uma universidade operacional, competitiva e heterônoma dentro do contexto do capitalismo acadêmico. Para isso, realizou-se, inicialmente, um paralelo entre o "novo espírito do capitalismo" de Boltanski e Chiapello, a "sociedade em rede" de Castells e a "modernidade líquida" de Bauman, explorando questóes relacionadas ao esfacelamento das relaçóes humanas e de trabalho. Tendo como pano de fundo as questóes levantadas por esses autores, buscou-se entender as consequências dessas transformaçóes para a universidade, retratando a Universidade Operacional como uma expressão de uma sociedade líquida-reticular. Por fim, buscou-se analisar tais mudanças sob a perspectiva da teoria do capitalismo acadêmico, explorando suas origens e expressóes contemporâneas no Brasil; assim como as maneiras pelas quais uma rede de atores internos e externos à universidade têm se engajado no processo de redefinição das fronteiras entre o público e o privado. Espera-se que este estudo possa contribuir para o avanço acerca do entendimento da situação atual da educação superior brasileira subsidiando o de(com)bate sobre a desconfiguraçáo da universidade aprofundada no contexto do capitalismo acadêmico.
\end{abstract}

Palavras-chave: Capitalismo acadêmico. Universidade Operacional. Novo espírito do capitalismo. Sociedade em rede. Modernidade líquida.

\footnotetext{
*Este artigo está vinculado ao projeto de pesquisa que originou a dissertação intitulada $A$ ascensão da lógica financeira sob a perspectiva da teoria do capitalismo acadêmico: consequências para a formação do engenheiro de produção, realizada na Universidade Federal de São Carlos (UFSCar), campus Sorocaba, e foi financiado pela Coordenaçáo de Aperfeiçoamento de Pessoal de Nível Superior (CAPES) (processo $\mathrm{n}^{\mathrm{o}}$ 1601669).

${ }^{1}$ Universidade de São Paulo, Escola Politécnica, Departamento de Engenharia de Produção São Paulo (SP), Brasil. E-mail: tiagosigahi@usp.br

${ }^{2}$ Universidade Federal de São Carlos, Departamento de Engenharia de Produção - Sorocaba (SP), Brasil. E-mail: patrisal@dep.ufscar.br
}

DOI: 10.1590/ES0101-73302018187694 


\section{THE EMERGENCE OF THE OPERATIONAL UNIVERSITY: NETWORKS, LIQUIDITY AND ACADEMIC CAPITALISM}

ABSTRACT: This article aimed to explore how new forms of capital and organization of human life have contributed to the construction of a fertile scenario for the consolidation of an operational, competitive and heteronomous university within the context of academic capitalism. First, we draw a parallel between Boltanski and Chiapello's "new spirit of capitalism", Castells's "network society" and Bauman's "liquid modernity", exploring issues related to the breakdown of human and labor relations. Building on the contributions of these authors, we discussed the consequences of such transformations for the university by portraying the Operational University as an expression of the net-reticular society. Finally, we analyzed such changes from the perspective of the theory of academic capitalism, exploring their origins and contemporary expressions in Brazil; as well as the ways through which a network of actors inside and outside university have been engaged in the process of redefining the boundaries between public and private. We hope this study may contribute to advance in the understanding of the current situation of Brazilian higher education by subsidizing the debate/combat concerning the university's deconfiguration deepened in the academic capitalist context.

Keywords: Academic capitalism. Operational University. The New Spirit of Capitalism. Network society. Liquid modernity.

\section{L'ÉMERGENCE DE L'UNIVERSITÉ OPÉRATIONNELLE: RÉSEAUX, LIQUIDITÉ ET CAPITALISME ACADÉMIQUE}

RESUME: Cet article vise à explorer comment les nouvelles formes de capital et de l'organisation de la vie humaine ont contribué à la construction de milieu fertile pour la consolidation d'une université d'exploitation, compétitive et hétéronome dans le contexte du capitalisme académique. Pour cela, au départ, il y aura un parallèle entre le "nouvel esprit du capitalisme » de Boltanski et Chiapello, "société en réseau » de Castells et " modernité nette » de Bauman, explorant des questions liées à la rupture des relations humaines et professionnelles. Dans le contexte des questions soulevées par ces auteurs, nous cherchons à comprendre les conséquences de ces changements pour l'université, représentant l'Université Opérationnelle comme une expression du monde liquide réticulaire. Enfin, on essaye d'analyser ces changements du point de vue du capitalisme académique, en explorant ses origines et expressions contemporaines au Brésil; ainsi que la façon dont un réseau d'acteurs internes et externes à l'université se sont engagés dans la remise à zéro frontière entre les secteurs public et privé. On s'attend à ceque cette étude contribuera à l'avancement de la compréhension de la situation actuelle de l'enseignement supérieur du Brésil en subventionnant le (avec) frappe sur le mutiler de l'université.

Mots-clés: Capitalisme académique. Université Opérationnelle. Nouvel esprit du capitalisme. Société en réseau. Modernité nette. 


\section{Introdução}

$\grave{A}$

emergência da sociedade do conhecimento, o debate da educação foi transformado em assunto de homens de negócios, banqueiros e estrategistas políticos (LEHER, 1999). Juntamente com governos, corporações e instituições educacionais, e balizados pelas ideias de eficiência, produtividade e competitividade, tais atores têm trabalhado ativamente na construção de um mercado da educação superior.

A introdução de uma lógica empresarial no campo educacional pode ser percebida por meio de diferentes vias: publicação de relatórios por influentes órgãos multilaterais (e.g., Banco Mundial, Organização das Nações Unidas para a Educação, Ciência e Cultura - UNESCO) contendo orientaçóes de cunho neoliberal ${ }^{1}$; utilização de linguagem gerencial no meio acadêmico; expansão desenfreada de faculdades privadas; criação de artefatos legais; atuação de fundos de investimento nacionais e internacionais; atuação de fundações privadas junto a entidades estudantis; entre outras.

De acordo com Chauí (2016), é nesse cenário que ocorre a passagem da universidade pública da condição de instituição à de organização. Tal transformação, segundo a autora, está relacionada à fragmentação de todas as esferas da vida social. Nesse sentido, este artigo pretendeu explorar como novas formas de capital e de organização da vida humana contribuem para a construção de um cenário fértil para o surgimento de uma universidade operacional, competitiva e heterônoma (SGUISSARDI, 2008b; 2013; DIAS SOBRINHO, 2014; 2015; CHAUÍ, 2016) dentro de um contexto de capitalismo acadêmico (SLAUGHTER; LESLIE, 1997; SLAUGHTER; RHOADES, 2004).

Para isso, realizou-se, inicialmente, um paralelo entre o "novo espírito do capitalismo" de Boltanski e Chiapello (2009), a "sociedade em rede" de Castells (1999) e a "modernidade líquida" de Bauman (2001), explorando-se questóes relacionadas ao esfacelamento das relaçóes humanas e de trabalho. Buscou-se, com isso, revelar as condiçôes que propiciaram a emergência do capitalismo acadêmico no Brasil.

Em seguida, tendo como pano de fundo as contribuiçôes desses autores, buscou-se melhor entender as consequências dessas transformaçôes para a universidade brasileira, retratando-se a Universidade Operacional (CHAUÎ́, 2016) como a expressão de um mundo líquido-reticular.

Por fim, buscou-se analisar tais mudanças na perspectiva da teoria do capitalismo acadêmico (SLAUGHTER; RHOADES, 2004), explorando desde suas origens até as expressóes contemporâneas no Brasil; assim como as maneiras pelas quais uma rede de atores - universidades, professores, alunos, policy makers, órgáos multilaterais, fundaçôes privadas, CEOs-celebridade (CEO - Chief Executive Officer, Diretor Executivo), fundos de investimento, grupos educacionais - engajase no processo de redefinição das fronteiras entre o público e o privado. 


\section{O espírito do capitalismo: o novo "grande" só pode enraizar-se em si mesmo}

Em livro que se tornou um marco no estudo das transformaçóes do capital, os sociólogos Boltanski e Chiapello (2009) desenvolveram a noção de "espírito do capitalismo", conceito que simboliza a ideologia que "justifica" o engajamento no capitalismo. Em outras palavras, é o conjunto de crenças associadas à ordem capitalista que contribui para justificar, sustentar e conferir sentido a essa ordem, legitimando seus modos de ação e dando respaldo à adesão ao estilo de vida coerente com ela (BOLTANSKI; CHIAPELLO, 2009, p. 42).

Esses autores identificam três diferentes configurações ideológicas ("espíritos do capitalismo") que emergem em períodos distintos. Tais configuraçôes, reveladas pela homogeneidade dos discursos de cada período, não são temporalmente estanques, uma vez que os espíritos antecessor e sucessor se interseccionam em grande parte. Ainda assim, traços característicos de cada período podem ser identificados, como mostra o Quadro 1.

O primeiro espírito do capitalismo estaria sintonizado com as formas do capitalismo essencialmente familiar: o destino e a vida da empresa eram fortemente associados aos destinos de uma família e os proprietários eram conhecidos pessoalmente por seus empregados. Em busca de legitimaçâo, seus defensores justificavam-se com base em constructos do bem comum, como a "crença no progresso, no futuro, na ciência, na técnica, nos benefícios da indústria", havendo pouca referência "ao liberalismo econômico, ao mercado ou à economia acadêmica". Ainda nesse período, o advento de novos meios de comunicação e do trabalho assalariado possibilitou a "libertação", sobretudo geográfica, dos mais jovens (BOLTANSKI; CHIAPELLO, 2009, p. 49-51).

O segundo espírito do capitalismo passar a ter como figura central o diretor, dirigente assalariado ou executivo, habitado pela vontade de aumentar ilimitada-

\section{Quadro 1}

Configurações ideológicas dos espíritos do capitalismo.

\begin{tabular}{|l|c|c|c|}
\hline $\begin{array}{l}\text { Espírito do } \\
\text { capitalismo }\end{array}$ & Primeiro & Segundo & Terceiro \\
\hline $\begin{array}{l}\text { Período de pleno } \\
\text { desenvolvimento }\end{array}$ & Fins do século XIX & $1930-1960$ & 1990 -atual \\
\hline Figura central & $\begin{array}{c}\text { Burguês } \\
\text { empreendedor }\end{array}$ & Diretor/Executivo & $\begin{array}{c}\text { Aquele que é rápido, } \\
\text { livre, escapadiço, } \\
\text { desengajado }\end{array}$ \\
\hline $\begin{array}{l}\text { Traços } \\
\text { característicos }\end{array}$ & $\begin{array}{c}\text { Associação ao } \\
\text { capitalismo familiar }\end{array}$ & $\begin{array}{c}\text { Incentivo à busca do } \\
\text { gigantismo da empresa }\end{array}$ & $\begin{array}{c}\text { Empresa "enxuta" } \\
\text { eem rede"; capital } \\
\text { "leve" e "flutuante" }\end{array}$ \\
\hline
\end{tabular}

Fonte: elaborado com base em Boltanski e Chiapello (2009) e Bauman (2001; 2007; 2009). 
mente o tamanho da empresa. Pode ser associado ao que Bauman (2001, p. 72-77) chama de capitalismo "pesado", em sua fase "volumosa", "imóvel” ou "enraizada". Persegue-se a ideia da grande empresa centralizada e burocratizada, fascinada pelo gigantismo, pela produção em massa, baseada em economias de escala, padronização de produtos e organização racional do trabalho (BOLTANSKI; CHIAPELLO, 2009, p. 50). O fordismo era a autoconsciência da sociedade (BAUMAN, 2001, p. 75).

O ideal de ordem industrial era encarnado pelos engenheiros pelas crenças no progresso, na ciência e na técnica, na produtividade e na eficácia. Os quadros profissionais das empresas passaram a ter a presença crescente de supervisores qualificados por diplomas universitários. A empresa ideal do segundo espírito possuía alta atratividade e estímulo junto a jovens recém-formados que vislumbravam a oportunidade de atingir posiçóes de poder, "a partir das quais se pudesse mudar o mundo" (BOLTANSKI; CHIAPELLO, 2009, p. 50-52). Ocorrem nessa fase a atenuação da luta de classes e a dissociação entre propriedade do capital e controle empresarial.

Para atender à demanda dos executivos por "garantias", surgem dispositivos, tais como: gerenciamento das carreiras nas grandes empresas; instauração da aposentadoria; ampliação do número de formas jurídicas do contrato de trabalho assalariado; além do próprio gigantismo das organizações que constituíam "ambientes protetores capazes de oferecer não só perspectivas de carreira, mas também infraestrutura para a vida cotidiana” (BOLTANSKI; CHIAPELLO, 2009, p. 59).

Por sua vez, o terceiro espírito do capitalismo - cuja consolidação está em curso - traz consigo um modelo de empresa totalmente novo, que tem se reinventado em torno de atributos como "enxuto", "leve", "sem adiposidades". Para os autores:

A imagem típica da empresa moderna hoje em dia é de um núcleo enxuto rodeado por uma miríade de fornecedores, serviços terceirizados, prestadores de serviços e trabalhadores temporários que possibilitam variar os efetivos segundo a atividade, empresas coligadas. Fala-se então em rede de empresas (BOLTANSKI; CHIAPELLO, 2009, p. 102).

Nesse novo cenário, o capital se torna exterritorial, leve, desembaraçado e solto numa medida sem precedentes (BAUMAN, 2001, p. 188). Ganham elevada amplitude os temas da concorrência e da mudança permanente e cada vez mais rápida das tecnologias e dos formatos organizacionais, e em praticamente todos os textos da imprensa de negócios da época são encontrados "conselhos" para a implantação de uma organização flexível capaz de "surfar sobre todas as ondas" (BOLTANSKI; CHIAPELLO, 2009, p. 100).

O terceiro espírito traz a apologia à mudança e ao risco. A mobilidade e a flexibilidade substituem a valorização da ideia de garantia da época anterior (BOLTANSKI; CHIAPELLO, 2009, p. 121). Esse é o tempo do capita- 
lismo de software e da modernidade leve (BAUMAN, 2001, p. 148). A empresa industrial centralizada e burocratizada, agora percebida como um acúmulo de vínculos contratuais, perde sua forma, pois suas fronteiras se tornam indistintas, liquefeitas (BOLTANSKI; CHIAPELLO, 2009, p. 103).

O trabalho também sofre profundas transformaçóes. Os membros de uma mesma equipe não funcionam obrigatoriamente juntos do ponto de vista físico - trabalham em rede. A questão do controle torna-se a preocupação central dos empresários, que chegam à conclusão de que a solução é que as pessoas se autocontrolem, deslocando assim "a coerção externa dos dispositivos organizacionais para a interioridade das pessoas" (BOLTANSKI; CHIAPELLO, 2009, p. 110).

Nesse novo universo, percebido como "múltiplo, complexo e rápido e, portanto, como ambíguo, vago e plástico" (THRIFT, 1997 apud BAUMAN, 2001, p. 148), as novas palavras de ordem são criatividade, reatividade e flexibilidade. O novo "grande" - aquele que tem sucesso e/ou é admirado - deve ser capaz de trabalhar com os mais variados perfis de pessoas; mostra-se aberto e flexível sempre que necessário; e está permanentemente disposto a mudar de projeto e a adaptar-se a novas circunstâncias (BOLTANSKI; CHIAPELLO, 2009, p. 121-124).

No mundo reticular, as pessoas precisam aprender a gerir um novo tipo de capital pessoal. A noção fundamental da concepção da vida laboral é a de "empregabilidade", que designa a capacidade de que as pessoas precisam ser dotadas para que se recorra a elas nos projetos. A segurança da carreira — proporcionada pelos dispositivos do segundo espírito - é substituída pela sucessão de projetos. "As pessoas náo farão carreira, mas passarão de um projeto a outro, pois o sucesso em dado projeto lhes possibilitará acesso a outros projetos mais interessantes", e assim sucessiva e ilimitadamente. Por definição, cada projeto é diferente, novo e inovador e, desse modo, esta é a oportunidade de ser apreciado pelos outros e poder ser chamado para outro negócio (BOLTANSKI; CHIAPELLO, 2009, p. 125).

A vida social não é mais apresentada na forma de uma série de direitos e deveres nem na forma de assalariados inseridos num conjunto hierárquico cujos degraus são possíveis de galgar, e sim de "uma multiplicidade de encontros e conexóes temporárias, mas reativáveis; em grupos diversos, realizados em distâncias sociais, profissionais, geográficas e culturais eventualmente muito grandes" (BOLTANSKI; CHIAPELLO, 2009, p. 135).

O "grande" é leve porque está liberto do peso de suas próprias paixóes e de seus valores e, por assim ser, ele não é crítico (BOLTANSKI; CHIAPELLO, 2009, p. 157), é dócil, incapaz ou "não desejoso de oferecer resistência organizada a qualquer decisão que o capital venha a tomar" (BAUMAN, 2001, p. 189); sacrifica certa interioridade e fidelidade a si mesmo, para ajustar-se melhor às pessoas com as quais entra em contato e às situaçôes; só pode enraizar-se em si mesmo "única instância dotada de certa permanência num mundo complexo, incerto e móvel” (BOLTANSKI; CHIAPELLO, 2009, p. 158). 


\section{0 mundo líquido-reticular²: a existência como atributo relacional e os contratos do tipo "enquanto durar a satisfação"}

A vida, portanto, nesta que podemos chamar de "sociedade em rede" (CASTELLS, 1999), é concebida como uma sucessão de projetos, não importando o seu tipo - familiar, afetivo, educativo, religioso etc. O importante é "nunca estar sem projetos, sem ideias, ter sempre algo em vista, em preparaçáo"; a sucessão de projetos multiplica as conexóes e provoca a proliferação de seus elos, ampliando as redes - e "a ampliação da rede é a própria vida" (BOLTANSKI; CHIAPELLO, 2009, p. 142-143).

Em um "planeta atravessado por autoestradas da informação" (BAUMAN, 2007, p. 11), a infraestrutura tecnológica que constrói a rede define o novo espaço assim como as ferrovias definiam os mercados na economia industrial (CASTELLS, 1999, p. 502). Na lógica desse mundo, a própria existência é um atributo relacional: cada ser "existe em maior ou menor grau segundo o número e o valor das conexôes que passam por ele" (BOLTANSKI; CHIAPELLO, 2009, p. 160).

Para Castells (1999, p. 202), surge uma nova economia, que é capitalista, mas "um novo tipo de capitalismo, tecnológica, organizacional e institucionalmente distinto do capitalismo clássico"; existe um componente adicional e essencial na nova economia: as redes.

Enquanto o industrialismo é voltado para o crescimento da economia (maximização da produção), o novo modo de desenvolvimento - o informacionalismo - visa à acumulação de conhecimentos e maiores níveis de complexidade do processamento de informação. Nesse sentido, "a rede é especialmente apropriada para a geraçáo de laços fracos múltiplos, úteis no fornecimento de informaçóes e de novas oportunidades a baixo custo" (CASTELLS, 1999, p. 445). Na economia informacional, organizações bem-sucedidas são aquelas "capazes de gerar conhecimentos e processar informaçóes com eficiência; adaptar-se à geometria variável da economia global; ser flexível o suficiente para transformar seus meios tão rapidamente quanto mudam os objetivos" (CASTELLS, 1999, p. 233).

Nos tempos líquidos em que hoje vivemos, é necessário aprender no caminho - e depressa. $\mathrm{O}$ jogo da dominação não é mais jogado entre o "maior" e o "menor", e sim entre o mais rápido e o mais lento (BAUMAN, 2001, p. 234), pois "quando patinamos no gelo fino, o que nos salva é a velocidade" (BAUMAN, 2011, p. 115). Dominam os que são capazes de acelerar além da velocidade de seus opositores; os mais escapadiços, que possuem a habilidade de se desengajar; "pessoas com as mãos livres mandam em pessoas com as mãos atadas" (BAUMAN, 2001, p. 151), uma vez que: "[a] presente versão liquefeita, dispersa, espalhada e desregulada da modernidade [...] anuncia o advento do capitalismo leve e flutuante" (BAUMAN, 2001, p. 187). 
Corpo esguio e adequaçáo ao movimento, roupa leve e tênis, telefones celulares (inventados para o uso dos nômades que têm que estar constantemente em contato), pertences portáteis/descartáveis - são os principais objetos culturais da era da instantaneidade (BAUMAN, 2001, p. 162).

Para explicar essa nova versão da maneira como nos comportamos hoje, Bauman (2009, p. 151-153) faz uso de uma metáfora em que compara um projétil (ou bala de arma de fogo) a um míssil inteligente. Durante as guerras de trincheiras, nas quais os alvos permaneciam imóveis, as qualidades do projétil o tornavam uma arma ideal: no instante em que a bala era disparada, a direção e a distância a ser percorrida já haviam sido decididas e, se miradas da maneira correta, tinham destino certo. Contudo, basta o alvo adquirir a habilidade de se mover para tornar essa arma inútil, fato que se acentua ainda mais quando se move "de forma errática e imprevisível, confundindo os cálculos preliminares da trajetória planejada". Assim, "[f]az-se necessário então um míssil inteligente que possa mudar de direção no meio do caminho [...] que seja capaz de detectar imediatamente os movimentos do alvo [...] deduzir o ponto exato em que suas trajetórias se cruzarão" (BAUMAN, 2001, p. 152).

Hoje, é necessário aprender no caminho e mudar de direção quantas vezes for preciso. A escolha do "alvo" é feita enquanto prosseguimos (e o perseguimos).

Analogamente às "organizações em rede" de Castells (1999) — que mudam seus meios tão rapidamente quanto mudam seus objetivos - e aos mísseis inteligentes de Bauman, exige-se das pessoas que sejam capazes de aprender tanto quanto esquecer instantaneamente o que se aprendeu antes; que mudem de ideia e revoguem decisóes prévias sem hesitação ou lamento. Assim, múltiplos laços fracos dão sentido e forma às redes.

Nesse cenário difuso, incerto e de falta de segurança de longo prazo, a "satisfação instantânea parece ser uma estratégia razoável" (BAUMAN, 2001, p. 203). Paradoxalmente, é necessário saber adiar a satisfaçáo, pois vivemos em uma "cultura de cassino": "Na cultura de cassino, a espera é tirada do querer, mas a satisfação do querer também deve ser breve; deve durar apenas até que a bolinha da roleta corra de novo, ter tão pouca duração quanto a espera, para não sufocar o desejo" (BAUMAN, 2001, p. 199).

Compromissos do tipo "até que a morte nos separe" se transformam em contratos do tipo "enquanto durar a satisfação", temporais por definição, por projetos (BAUMAN, 2001, p. 205); e estes, justamente por serem transitórios, se ajustam a um mundo em rede.

É nesse contexto de mudança da organização da vida humana, que se torna "fluida"; da estrutura social, que passa a ser em rede; do modo de desenvolvimento baseado na acumulação e no processamento de informação; e do capital leve e flutuante, que ocorre a introdução da lógica de mercado nas universidades públicas. 


\section{De instituição à organização: a universidade operacional, competitiva e heterônoma}

A análise de Chauí (1999; 2001; 2003; 2014; 2016) sobre o avanço das ideias neoliberais no campo da educação superior está apoiada essencialmente na questão da mudança da natureza da educação, ou seja, a sua transformação de direito social em um serviço. Desse fato decorre a passagem da universidade pública da condição de instituição à de organização, como mostra o Quadro 2.

A universidade como instituição busca um conhecimento desinteressado e isento de valores, aproximando-se do que Slaughter e Rhoades (2004, p. 76) chamam de Public Good Model of Research, guiado pelas normas mertonianas, pautado nas ideias da universalidade e do livre fluxo do conhecimento.

Quando ocorre a transformação da educação em serviço, são introduzidos no meio acadêmico termos como "qualidade universitária", "avaliação uni-

\section{Quadro 2}

Diferenças entre instituição e organização.

\begin{tabular}{|c|c|c|}
\hline & Instituiçáo universitária & Organizaçáo universitária \\
\hline Objetivos & $\begin{array}{l}\text { Instituição social que busca o } \\
\text { conhecimento, a reflexão, a crítica e } \\
\text { a formação. }\end{array}$ & $\begin{array}{l}\text { Entidade administrada empresarialmente } \\
\text { tendo como horizonte o mercado, onde } \\
\text { compete com outras organizaçóes por } \\
\text { consumidores de serviços educacionais. }\end{array}$ \\
\hline $\begin{array}{l}\text { Referencia- } \\
\text { lidade }\end{array}$ & $\begin{array}{l}\text { Tem a sociedade como princípio e } \\
\text { referência normativa e valorativa; } \\
\text { questiona sua própria existência, } \\
\text { sua função, seu lugar no interior da } \\
\text { sociedade. }\end{array}$ & $\begin{array}{l}\text { Tem a si mesma como referência em } \\
\text { um contexto de competiçáo com outras } \\
\text { empresas educacionais; sabe (ou julga } \\
\text { saber) por que, para que e onde existe. }\end{array}$ \\
\hline Legitimidade & $\begin{array}{l}\text { Funda-se na ideia de um } \\
\text { conhecimento guiado por sua } \\
\text { própria lógica, por necessidades } \\
\text { imanentes a ele. }\end{array}$ & $\begin{array}{l}\text { Define-se pela prática social da } \\
\text { instrumentalidade (conjunto de meios } \\
\text { administrativos particulares para } \\
\text { obtenção de um objetivo particular). }\end{array}$ \\
\hline Qualidade & $\begin{array}{l}\text { Capacidade de enfrentar os } \\
\text { problemas científicos, humanísticos } \\
\text { e filosóficos postos pelas dificuldades } \\
\text { da experiência de seu próprio tempo. }\end{array}$ & $\begin{array}{l}\text { Balizada pelas ideias de eficiência e } \\
\text { eficácia; regida pelas ideias de gestáo, } \\
\text { planejamento, previsão, controle e } \\
\text { êxito. }\end{array}$ \\
\hline Autonomia & $\begin{array}{l}\text { Busca garantir que a universidade } \\
\text { seja regida por suas próprias normas, } \\
\text { democraticamente instituídas por } \\
\text { seus órgáos representativos, além de } \\
\text { assegurar critérios acadêmicos para } \\
\text { a vida acadêmica e independência } \\
\text { para definir a relaçáo com a } \\
\text { sociedade e o Estado. }\end{array}$ & $\begin{array}{l}\text { Significa o gerenciamento empresarial } \\
\text { da instituição e prevê que, para cumprir } \\
\text { as metas e alcançar os indicadores } \\
\text { impostos pelo contrato de gestáo, a } \\
\text { universidade tem "autonomia" para } \\
\text { "captar recursos" de outras fontes. }\end{array}$ \\
\hline
\end{tabular}

Fonte: elaborado com base em Chaui (1999; 2001; 2003; 2014; 2016). 
versitária" e "flexibilização da universidade" (CHAUÍ, 1999). A ciência torna-se uma força produtiva e a ideia de que a universidade pode ser dirigida segundo as mesmas normas e critérios com que se administra uma montadora de automóveis ou uma rede de supermercados passa a ser aceita (CHAUÍ, 2014).

A política de educação superior passa a ser tratada como um subconjunto da política econômica (SLAUGHTER; LESLIE, 2001) e surge a "universidade empreendedora" (CLARK, 1998); o ensino superior começa a ser entendido e vendido como produto e serviço para alunos/pais que, por sua vez, passam a ser concebidos como clientes/consumidores; a pesquisa passa a ser avaliada e valorizada - quase que apenas pelo seu potencial de gerar publicaçóes ou patentes.

Assim, a sociedade deixa de ser a referência da universidade, que se encontra inserida em um ambiente de competição onde alcançam êxito aqueles que são mais flexíveis, adaptáveis e eficientes; instala-se a cultura da performatividade que, por meio de medidas de desempenho quantitativas, fomenta relaçóes de competitividade entre instituiçóes, programas e pesquisadores (BALL, 2005). Torna-se imprescindível a capacidade de participar de vários projetos ao mesmo tempo - e de ser apreciado pelos outros para continuar sendo chamado. É preciso aprender e esquecer rapidamente, desengajar-se e não enraizar-se.

A universidade não mais precisa, necessariamente, enfrentar os problemas postos pelas dificuldades de seu tempo, superar o instituído. Como uma organização, as palavras de ordem são "eficiência", "eficácia", "produtividade"; é preciso diversificar formas de financiamento, gerar ganhos, bater metas, obter bom desempenho (financeiro, inclusive), mercadologicamente falando (CATANI; OLIVEIRA, 2000).

Perde-se a ideia de autonomia, de ser autor da norma, da regra e da lei, pois esta, agora, reduz-se à gestão de receitas e despesas de acordo com o contrato de gestão pelo qual o Estado estabelece metas e indicadores de desempenho (CHAUÍ, 2014). A autonomia "significa táo somente a liberdade para atender aos objetivos oficiais, mediante a competição por fundos e outros incentivos econômicos" (LÉDA; MANCEBO, 2009, p. 56). A nova autonomia é uma "autonomia para livremente conformar-se” (MEEK, 2002 apud SGUISSARDI, 2005, p. 20).

\section{A universidade operacional como expressão do mundo líquido-reticular}

Chauí (1999; 2001; 2003; 2014) mostra que, no Brasil, a transformação da universidade ocorreu em três etapas sucessivas: numa primeira fase, a "universidade clássica", voltada para o conhecimento, torna-se Universidade Funcional, voltada diretamente à formação rápida de mão de obra para o mercado de trabalho, período que corresponde ao "milagre econômico" dos anos 1970; 
nos anos 1980, surge a Universidade de Resultados, que pode ser assim chamada por direcionar seus esforços à empregabilidade dos futuros profissionais e à utilidade imediata de suas pesquisas; e, finalmente, em meados dos anos 1990, quando da ascensão da ideologia neoliberal, nasce a Universidade Operacional, ainda presente nos dias de hoje, regida por programas de eficácia organizacional, avaliada por índices de produtividade e voltada para si mesma. O Quadro 3 mostra as principais características de cada uma dessas fases.

Todas essas transformaçóes colocam em movimento a operacionalização das instituiçôes universitárias (CHAUÍ, 1999). A universidade não mais (re)age, ela opera:

- A docência, ainda que seja responsável por "formar novos docentes, incentivar novos pesquisadores e preparar profissionais para atividades não acadêmicas", não entra na medida da produtividade e, portanto, não faz parte da qualidade universitária (CHAUÍ, 1999; 2016);

\section{Quadro 3}

Fases da universidade pública brasileira no período 1970-atual.

\begin{tabular}{|c|c|c|c|}
\hline Universidade & Período & Orientaçáo & Principais características \\
\hline Funcional & $1964-1980$ & $\begin{array}{l}\text { Mercado } \\
\text { de trabalho }\end{array}$ & $\begin{array}{l}\text { Abertura indiscriminada de cursos superiores; } \\
\text { Subordinação do MEC ao Ministério do } \\
\text { Planejamento; } \\
\text { Voltada para a formação rápida de } \\
\text { profissionais para o mercado de trabalho; } \\
\text { Alteração de currículos, programas e } \\
\text { atividades para garantir inserçáo profissional } \\
\text { no mercado de trabalho. }\end{array}$ \\
\hline de Resultados & 1985-1994 & Empresas & $\begin{array}{l}\text { Crescimento do número de universidades } \\
\text { privadas; } \\
\text { Introdução da ideia de parceria universidade } \\
\text { pública-empresa privada; } \\
\text { Influência das empresas nos resultados } \\
\text { (pesquisa e formação) das universidades. }\end{array}$ \\
\hline Operacional & 1994- atual & $\begin{array}{l}\text { Voltada para } \\
\text { si mesma }\end{array}$ & $\begin{array}{l}\text { Estruturada por estratégias e programas de } \\
\text { eficácia organizacional; } \\
\text { Regida por contratos de gestão, normas e } \\
\text { padróes alheios à formação intelectual; } \\
\text { Avaliada por índices de produtividade; } \\
\text { Docente como trabalhador flexível; } \\
\text { Aumento de horas-aula; } \\
\text { Diminuiçáo do tempo de mestrados e } \\
\text { doutorados; } \\
\text { Multiplicação de comissóes e relatórios. }\end{array}$ \\
\hline
\end{tabular}

Fonte: elaborado com base em Chaui (2014; 2016). 
- O docente torna-se um trabalhador flexível. Sua atividade passa a ser entendida como correia de transmissão de informaçáo, reduz-se ao adestramento de novos pesquisadores e/ou a um meio de habilitaçáo rápida para graduados, que precisam entrar rapidamente num mercado de trabalho no qual se tornam obsoletos e descartáveis em pouco tempo (CHAUÍ, 2003; 2016);

- A seleção de docentes passa a ter como principal critério seu "potencial de pesquisa", expresso pela razáo entre o número de publicaçóes em um determinado período de tempo; ou porque, não tendo vocação para a pesquisa, aceita ser escorchado e arrochado por contratos flexíveis de trabalho, isto é, temporários e precários (CHAUÍ, 2016);

- Na pesquisa, não há mais tempo para a reflexão, a crítica, o exame de conhecimentos instituídos, sua mudança ou sua superação (CHAUÍ, 1999). Diversos são os instrumentos de controle, pressão e mensuraçáo de pesquisadores, por exemplo, conceitos Qualis, rankings, currículo lattes e medidas de desempenho (quantidade de publicações, participação em bancas, verbas para pesquisa, número de orientandos bolsistas etc.). Se por pesquisa entendermos a investigação de algo que nos lança na interrogação, que nos pede reflexão, descoberta, invençáo e criaçãa, então é evidente que não pode haver pesquisa na Universidade Operacional (CHAUÍ, 1999);

- $\quad$ Não se forma mais espíritos inquietos (RIBEIRO, 2014, p. 57); perde-se o significado de formação, que é o de "introduzir alguém ao passado de sua cultura e despertá-lo(a) às questóes que este passado engendra para o presente, estimulando a passagem do instituído ao instituinte" (CHAUÍ, 2003, p. 12).

A universidade deixou de ser uma instituição social e passou a ser uma organização prestadora de serviços, o que foi possibilitado pela forma com que se configura a sociedade: como "uma rede, móvel, instável, efêmera de organizaçôes particulares definidas por estratégias particulares e programas particulares, competindo entre si” (CHAUÍ, 2003, p. 7).

No jogo estratégico da competição no mercado, a organização se mantém e se firma se for capaz de propor áreas de problemas, dificuldades e obstáculos sempre novos, o que é feito pela fragmentação de antigos problemas em novíssimos microproblemas (CHAUÍ, 2016). A Universidade Operacional está pulverizada em micro-organizaçóes que ininterruptamente ocupam seus docentes e curvam seus estudantes a exigências exteriores ao trabalho do conhecimento (CHAUÍ, 2003, p. 7). Ainda que não deem prazer — ou causem desprazer —, o importante é nunca estar sem projetos, sem ideias, ter sempre algo em vista, em preparação; é preciso fazer "parcerias" que rendam publicaçóes, ser hábil para multiplicá-las, "fazer render"; criar sua própria rede é uma necessidade para prosperar - e sobreviver — no mundo acadêmico competitivo. 
$\mathrm{Na}$ Universidade Operacional é pré-requisito “ter sucesso" em um projeto para ser chamado para outro - é preciso ser dotado de "empregabilidade acadêmica". A questão, porém, como aponta Chauí (2016), é que a "medida do sucesso" é feita em termos compreensíveis para uma organização, isto é, em termos de custo-benefício, em quanto tempo, com que custo e quanto foi produzido. Não se indaga "o que" se produz, "como" se produz, "para que" ou "para quem" se produz (CHAUÍ, 1999). O importante é produzir; e produzir cada vez mais.

A permanência de uma organização "depende muito pouco de sua estrutura interna e muito mais de sua capacidade de adaptar-se celeremente a mudanças rápidas do ambiente". A redução do tempo entre a aquisição de um conhecimento e sua aplicação tecnológica é acentuada "a ponto dessa aplicação acabar determinando o conteúdo da própria investigação científica” (CHAUÍ, 2003, p. 7-9). O "grande" de Boltanski e Chiapello (2009), as "organizaçóes em rede" de Castells (1999), os mísseis inteligentes de Bauman (2001) e a Universidade Operacional de Chauí (2016): todos precisam ser flexíveis o suficiente para transformar os meios tão rapidamente quanto mudam os objetivos.

A cultura de cassino também se faz presente na Universidade Operacional. Não há tempo para refletir, descobrir, criar - o que, teoricamente, daria prazer ao pesquisador; "a satisfação do querer também deve ser breve, deve ter tão pouca duração quanto a espera, para não sufocar o desejo" (BAUMAN, 2001, p. 199).

A existência do pesquisador, seja ele sênior ou de início de carreira, é também um atributo relacional: ele existe em maior ou menor grau segundo o número e o valor das conexóes que passam por ele. Sua carreira não deixa de ser uma sucessão de projetos, que exige a multiplicação dessas conexôes e a proliferação de seus elos — a ampliação da rede passa a ser a própria carreira acadêmica.

Soma-se a isso a precarização do trabalho docente e a corrosão do significado de docência, o que faz com que professores e alunos sejam instados a se libertarem do peso de suas próprias paixóes e de seus valores. Para ser "grande", a aceitação de que somente é possível enraizar-se em si mesmo é uma condição necessária. O resultado disso é o esfacelamento das relaçóes humanas e de trabalho em uma universidade operacional, competitiva e heterônoma.

\section{Capitalismo acadêmico no Brasil: das origens às expressões contemporâneas}

Diversos são os estudos que buscam explicar como as tendências neoliberais têm moldado o campo da educação superior (SLAUGHTER; LESLIE, 1997; SLAUGHTER; RHOADES, 2004; CANTWELL; KAUPPINEN, 2014; SCHULZE-CLEVEN; OLSON, 2017; JESSOP, 2017; 2018). Tornam-se cada vez mais tênues as fronteiras entre o público e o privado, o que ocorre por meio da 
ação de uma rede de atores guiados pela ideologia "the market knows best" (MOK, 2001, p. 302) e pelo culto à performatividade (BALL, 2005).

O estudo seminal realizado por Slaughter e Leslie (1997) — aprimorado mais tarde por Slaughter e Rhoades (2004) —, que popularizou o termo "capitalismo acadêmico" ${ }^{3}$, inspirou um grande número de pesquisadores, tornando-se uma das linhas de pesquisa mais influentes no campo da educação superior (CANTWELL, 2015, p. 487). O avanço do estudo sobre o tema mostrou que esse fenômeno de reconfiguração de fronteiras não tem suas próprias fronteiras, tendo sido identificado nos mais variados contextos, como Alemanha (MÜNCH; BAIER, 2012), Austrália (COLLYER, 2013), Brasil (MARTINS, 2008; DIAS SOBRINHO, 2014; 2015; DIAS; SERAFIM, 2015), Canadá (METCALFE, 2010), China (MOK, 2001), Colômbia (CARABALLO, 2016), Coreia do Sul (HAN; HESHMATI, 2016), Estados Unidos (SLAUGHTER; CANTWELL, 2012; HERMANOWICZ, 2016a, 2016b; MCCLURE; TEITELBAUM, 2016), Finlândia (KAIDESOJA; KAUPPINEN, 2014), Japão (SHIBAYAMA, 2012), Quênia (JOHNSON; HIRT, 2011), Reino Unido (WATERMEYER, 2014), República Tcheca (STÖCKELOVÁ, 2014), entre outros.

No Brasil, os primeiros sinais do capitalismo acadêmico ocorreram no período da Universidade Funcional (CHAUÍ, 2016), quando teve início o processo de mercantilização das instituições de ensino (MARTINS, 2009; DIAS SOBRINHO, 2010). Nesse intervalo, que compreende desde os anos 1964 até 1980, ocorrem diversas transformaçóes no campo da educaçáo superior brasileira que impulsionam o movimento em direçáo ao mercado:

- $\quad$ Em 1966, o Brasil encomenda o Plano Atcon junto aos Estados Unidos (MARTINS, 2009, p. 19), que, fazendo uso de um discurso baseado nas ideias de "eficiência e desempenho", recomenda novas formas de financiamento das universidades públicas brasileiras;

- Por meio da Lei de Educaçáo Superior (Reforma de 1968), o governo permite a criação de estabelecimentos privados isolados de cunho marcadamente profissionalizante (MARTINS, 2009, p. 17);

- Expansão desenfreada de instituiçóes de ensino superior (IES) privadas visando a um novo nicho de mercado (nova classe média em busca de ascensão social por meio do diploma) (CUNHA, 2007; CHAUÍ, 2016);

- O Banco Mundial (BM) torna-se o maior depositário internacional de estudos e estatísticas sobre os países em desenvolvimento (LEHER, 1999).

Na fase da Universidade de Resultados (1985-1994) (CHAUÍ, 2016), o capitalismo acadêmico começa a ganhar contornos mais definidos:

- Proprietários de IES privadas, ao notarem potenciais vantagens competitivas relacionadas ao aumento da diversificação de cursos em uma mesma 
instituição, aceleraram o processo de fusão entre pequenas IES, o que, segundo Martins (2009), triplicou o número de universidades particulares;

- O BM publica o relatório intitulado Higher education: the lessons of experience (BANCO MUNDIAL, 1994), documento-chave no processo de propagaçấo de diversos conceitos relacionados ao capitalismo acadêmico, recomendando que as autoridades dos países em desenvolvimento ficassem "atentas aos sinais do mercado" (SGUISSARDI, 2008a, p. 1000).

Finalmente, na fase da Universidade Operacional (1994-atual), que hoje está em curso (CHAUÍ, 2016), é inaugurada uma sucessão de governos que seguem boa parte da cartilha do BM (MANCEBO; SILVA JR., 2015), conforme sintetizado no Quadro 4.

As expressões mais recentes do capitalismo acadêmico brasileiro podem ser reconhecidas não só nas medidas adotadas pelo Governo Temer, mas também na mobilização do setor empresarial:

- Aprovação da Proposta de Emenda à Constituição no 55/2016 (PEC 55), que institui o Novo Regime Fiscal no âmbito dos Orçamentos Fiscal e da Seguridade Social da União, a qual representa, segundo Leher (2016), o fim da gratuidade da universidade pública, esta que é responsável por mais de $85 \%$ da pesquisa no Brasil;

- Crescente envolvimento de empresários no meio político-educacional, como indicam a nomeação da ex-Lemann Fellow (apelido daqueles que receberam bolsa da Fundação Lemann de Jorge Paulo Lemann) Teresa Pontual para subsecretaria do Ministério da Educação (MEC); e a participação de diretores de empresas como Itaú, Unibanco, Gerdau, Ambev, Natura, entre outras, em audiência pública destinada à discussão sobre o futuro da educação brasileira (BORGES, 2016);

- Intenso movimento de fusóes e aquisiçóes empreendido por grandes grupos educacionais privados e por fundos de investimento nacionais e internacionais, por exemplo, Apollo Group, Carlyle, Laureate International University, Whitney International University System (SGUISSARDI, 2008a), GP Investimentos, UBC Pactual, Capital Group e Cartesian Group (CARVALHO, 2013); com destaque para o grupo Kroton Educacional, que detém as faculdades Anhanguera, Fama, LFG, Pitágoras, Unic, Uniderp, Unime e Unopar (MELO; SALOMÃO, 2016), e possui no seu quadro de investidores fundos de investimento como Blackrock Inc., Capital World Investors e o GIC Private Limited;

- Dominaçáo da educação superior pelo setor privado, que dispóe de $88 \%$ das IES; $78 \%$ do total de matrículas, sendo 73 e $86 \%$, respecti- 
vamente, entre presenciais e ensino a distância $(\mathrm{EaD}) ; 68 \%$ dos cursos presenciais; e 57\% dos docentes (INEP, 2016);

- Considerando o período de 2012 a 2014, houve alta valorização das ações de empresas como Kroton (299,59\%), Estácio (245,50\%) e Anhanguera $(85,8 \%)$; comparativamente, empresas tradicionais diminuíram seu valor, como Vale $(-23,83 \%)$ e Petrobras $(-34,11 \%)$ (SILVA JR.; PIMENTA, 2014);

- A difusão das ideias de atores emblemáticos do empreendedorismo nacional, do mercado de capitais e da gestão de corporaçóes nacionais e internacionais, como o trio Jorge Paulo Lemann, Marcel Telles e Beto Sicupira, que inspira legióes com o discurso meritocrático disseminado no interior das universidades por meio de organizaçóes estudantis como Empresas Júnior, Clubes de Consultoria e Ligas de Mercado Financeiro (SIGAHI; SALTORATO, 2017).

\section{Quadro 4}

Governos e medidas de cunho neoliberal referentes à educação superior durante a fase da Universidade Operacional (1994-atual).

\begin{tabular}{|c|c|}
\hline Gestão & Medidas do governo \\
\hline $\begin{array}{l}\text { Cardoso } \\
(1995-2002)\end{array}$ & $\begin{array}{l}\text { Criação do Conselho Nacional de Educação (CNE); } \\
\text { Lei de Diretrizes e Bases da Educação (LDB) } 1996 \text { (Lei no 9.394/96); } \\
\text { Decretos no 2.026/96, 2.208/97 e 2.306/97 } \\
\text { Criação do Fundo de Financiamento Estudantil (FIES); } \\
\text { Plano Nacional de Educação (PNE) (Lei no 10.172/2001). }\end{array}$ \\
\hline $\begin{array}{l}\text { Lula } \\
(2003-2010)\end{array}$ & $\begin{array}{l}\text { Sistema Nacional de Avaliação da Educação Superior (SINAES) (Lei no } \\
\text { 10.861/2004); } \\
\text { Escolas técnicas (Decreto no 5.225/2004); } \\
\text { Parcerias público-privadas (Lei no 11.079/2004); } \\
\text { Lei da Inovação Tecnológica (Lei no 10.973/2004); } \\
\text { Programa Universidade para Todos (PROUNI) (Lei no 11.502/2005); } \\
\text { Educaçáo a distância (EaD) (Decreto no 5.622/2005); } \\
\text { Universidade Aberta do Brasil (UAB) (Decreto no 5.800/2006); } \\
\text { Reestruturaçáo e Expansão das Universidades Federais (REUNI) (Decreto no } \\
\text { 6.096/2007). }\end{array}$ \\
\hline $\begin{array}{l}\text { Roussef } \\
\text { (2011-2016) }\end{array}$ & $\begin{array}{l}\text { Plano Nacional de Pós-Graduação (PNPG) (2011-2020); } \\
\text { Câmara de Políticas de Gestão, Desempenho e Competitividade (CGDC) } \\
\text { (Decreto no 7.478/2011); } \\
\text { Programa Nacional de Acesso ao Ensino Técnico e Emprego (PRONATEC) } \\
\text { (Lei no } 12.513 / 2011) ; \\
\text { PNE (2014-2024; Lei no 13.005/2014); } \\
\text { Novo Código Nacional de Ciência, Tecnologia e Inovação (Lei no 13.243/2016). }\end{array}$ \\
\hline
\end{tabular}

Continua... 


\section{Quadro 4}

Continuação.

\begin{tabular}{|c|c|c|}
\hline Gestáo & Objetivos/Efeitos & Referência(s) \\
\hline $\begin{array}{l}\text { Cardoso } \\
(1995-2002)\end{array}$ & $\begin{array}{l}\text { Ampliação de vagas sem custo ao Estado; } \\
\text { Institucionaliza o modelo de estabelecimentos } \\
\text { educacionais lucrativos e reconhece a educação } \\
\text { superior como um serviço comercializável; } \\
\text { Privilegia na avaliaçáo de IES indicadores de caráter } \\
\text { gerencial; } \\
\text { Vinculação da educação profissional a objetivos } \\
\text { estritos do mercado; } \\
\text { Compra pelo Estado de vagas ociosas em IES } \\
\text { particulares. }\end{array}$ & $\begin{array}{l}\text { Catani e Oliveira } \\
\text { (2003), Cunha (2007), } \\
\text { Sguissardi (2008a), } \\
\text { Dias Sobrinho (2010), } \\
\text { Carvalho (2013), } \\
\text { Mancebo e Silva Jr. } \\
\text { (2015). }\end{array}$ \\
\hline $\begin{array}{l}\text { Lula } \\
(2003-2010)\end{array}$ & $\begin{array}{l}\text { Desenvolvimento de mecanismos de controle e } \\
\text { mensuraçáo da eficácia e eficiência institucional; } \\
\text { Ampliaçáo da capacidade gerencial das } \\
\text { universidades (incluindo a contratação de } \\
\text { profissionais não acadêmicos); } \\
\text { Criação de novas formas de educação, novos } \\
\text { mercados, novos circuitos de conhecimento e novos } \\
\text { fluxos de financiamento; } \\
\text { Introdução da lógica da administração de } \\
\text { resultados nas universidades. }\end{array}$ & $\begin{array}{l}\text { Sguissardi (2008a), Léda } \\
\text { e Mancebo (2009), } \\
\text { Silva Jr., Ferreira e Kato } \\
\text { (2013), Mancebo e Silva } \\
\text { Jr. (2015). }\end{array}$ \\
\hline $\begin{array}{l}\text { Roussef } \\
(2011-2016)\end{array}$ & $\begin{array}{l}\text { Implementa um sistema de avaliação baseado nos } \\
\text { valores da pesquisa empreendedora; } \\
\text { Institui um grupo de atores (empresários do alto } \\
\text { escaláo) que visa obter influência na gestáo das IES; } \\
\text { Flexibiliza as regulamentaçóes de produçáo do } \\
\text { conhecimento; } \\
\text { Intensifica o individualismo e a competitividade } \\
\text { nas relaçôes de trabalho. }\end{array}$ & $\begin{array}{l}\text { Peroni (2012), Silva Jr., } \\
\text { Ferreira e Kato (2013), } \\
\text { Silva Jr. e Sguissardi } \\
\text { (2013), Silva Jr. e Kato } \\
(2016)\end{array}$ \\
\hline
\end{tabular}

\section{Considerações finais}

Visando tecer/retratar o pano de fundo sobre o qual se desvela o avanço do capitalismo acadêmico, este artigo entrelaçou um conjunto de referenciais teóricos (Boltanski e Chiapello, Bauman, Castells e Chauí) em torno da temática da "liquidez", cara à compreensáo do atual contexto de esfacelamento das relaçóes humanas e de trabalho. Apesar desses referenciais convergirem em torno de tal temática, eles guardam posições teórico-metodológicas não convergentes entre si (GRÜN, 2003; SWEDBERG, 2004; CASADEI, 2009; ARRUDA, 2010; OLIVEIRA; MEIRA, 2013; KIRSCHBAUM, 2015).

Tomando como exemplo as obras de Castells (1999) e Boltanski e Chiapello (2009); enquanto o primeiro apresenta um farto conjunto de dados (de teses 
acadêmicas a estatísticas da Organização das Naçóes Unidas - ONU e do BM) sobre inúmeros países visando identificar mudanças estruturais na sociedade e propor uma teoria transcultural da economia e da sociedade, supondo a emergência de uma nova estrutura social na Era da Informação; Boltanski e Chiapello (2009) analisam tais mudanças de forma qualitativa, restringindo-se ao território francês e sem empregar fontes estatísticas. Esses autores adotam o tipo ideal weberiano para distinguir as transformaçóes capitalistas no período entre 1968 e 1998 e então circunscrever as concepçóes distintivas da expressão capitalista mais recente, a partir da literatura voltada para a gestáo empresarial (considerando tanto seu aporte técnico como seu apelo moral), um dos principais espaços, segundo os autores, de inscrição do "espírito" capitalista que eles buscam conceber (OLIVEIRA; MEIRA, 2013).

As escolhas teórico-metodológicas dos autores aqui amalgamados estão associadas à identificação pessoal de cada um deles com as possibilidades e os alcances desde seus objetos de estudo e ferramentas de análise de dados até seus projetos políticos e experiências/trajetórias pessoais em realidades distintas, resultando em tomadas de posiçôes teórico-metodológicas não convergentes entre si, mas que de forma alguma inviabilizaram o propósito deste artigo, que foi, a partir deste mosaico, explorar a dissolução das fronteiras entre o público e o privado no campo da educação superior no Brasil; a submissão da universidade pública aos interesses empresariais; e a instauração de uma lógica de cunho financista sobre ela, degenerando não só o modo como conduzi-la, mas também como percebê-la e experimentá-la.

A "instigante promessa da inserção profissional" (GRÜN, 2003, p. 5) em um mundo líquido-reticular subordina-se à comunhão de seus fiéis às virtuoses inscritas no novo "espírito" do capitalismo materializado em redes conectadas por laços fracos, temporários (e fluidos), que engendram melhor custo-benefício comparado à rigidez inerente aos laços fortes que engessam as possibilidades de deslocamentos rápidos em busca de posições mais vantajosas/privilegiadas na rede. Entre tais virtudes figuram a conectividade, adaptabilidade, flexibilidade, polivalência, empregabilidade, autonomia, predisposição ao risco, dentre outras que compóem o receituário do discurso/credo empresarial voltado para o recrutamento/doutrinação de novos fiéis, acenando com a crença em um mundo edificante, alcançável por todos os conectáveis.

O processo de legitimação dessa nova ordem na reorganização da sociedade a partir de meados das décadas de 1980 e 1990, atinente com o projeto neoliberal (e seu corolário, a lógica de livre mercado), logrou, assim, engajar atores dos mais variados espaços (organizacional, financeiro, acadêmico, jurídico etc.) em um amplo processo de financeirização econômica que agora se esgueira educação superior adentro, materializado na institucionalização da universidade operacional instrumentalizada, entre outros, pelos mecanismos do capitalismo acadêmico.

Considerando tal "mundialização do capital presidida pelas finanças" (CHAUÍ, 1999), a perspectiva do capitalismo acadêmico, explícita nas políticas 
de ciência, tecnologia e inovação, tem avançado por meio da atuação conjunta tanto de atores internos (e.g., reitores, professores, alunos) como externos (e.g., governos, corporaçóes, órgãos multilaterais, fundaçóes privadas) a ela — inclusive ela própria. Assim, para superar efetivamente os desafios impostos às universidades brasileiras, ainda é preciso adensar o debate a respeito de seus condicionantes e consequências, envolvendo, por exemplo, o discurso da "quarta missão da universidade", o culto ao "inovacionismo", a obsessão pelos rankings internacionais e a flexibilização curricular proposta pelo Processo de Bolonha (DIAS; SERAFIM, 2015, p. 336).

À imagem deste trabalho, outros estudos têm tomado emprestados conceitos correlatos tratados por diversos autores (cujas posiçóes teórico-metodológicas também nem sempre convergem entre si) para explorar as temáticas associadas ao contexto do capitalismo acadêmico. Por exemplo, como no caso do emprego da noção de campo bourdiesiana para retratar os atores e suas respectivas açóes no âmbito da consolidação deste campo, conceito central tanto aos strategic action fields tratados por Fligstein e McAdam (CANTWELL, 2015) como ao habitus de Pierre Bourdieu (MENDOZA; KUNTZ; BERGER, 2012). Estudos futuros certamente se debruçarão visando explorar outras teorias e conceitos diversos de forma a contribuir para a compreensão das mudanças impetradas pelo capitalismo acadêmico.

Este estudo buscou explorar a formação, passando pela consolidação até as expressóes contemporâneas do capitalismo acadêmico no Brasil, considerando esse processo de institucionalizaçáo anexo a um "mundo líquido-reticular", onde afloram condições profícuas à ascensão de uma lógica financista sobre o espaço acadêmico. Tal dinâmica tem logrado êxito ao engajar atores egressos dos mais variados espaços (organizacional, financeiro, jurídico, acadêmico etc.) que, manuseando seus respectivos capitais simbólicos, têm produzido (imposto e reproduzido) novos sentidos acerca do que deva ser e consequentemente de como deva ser gerido, experimentado e vivido esse espaço. Espera-se, assim, subsidiar o de(com)bate acerca da desconfiguração desse espaço "onde se pensa o que normalmente não se pensa e/ou onde se pensa de outro e novo modo aquilo que normalmente é pensado ou já estava pensado" (DERRIDA, 2001 apud WAIZBORT, 2015, p. 63); do contrário, qual o sentido da universidade?

\section{Notas}

1. Por neoliberal os autores entendem o conjunto de convençôes cognitivas que a partir de meados da década de 1980 passaram a argumentar a favor da redução da atuação do Estado na economia (inclusive nas áreas da Previdência Social, da Saúde e da Educação) e a favor da disciplina de mercado (inclusive, e principalmente, o de capitais); da desregulamentação econômica/financeira/trabalhista decorrente de tal afastamento estatal; da privatização de bens públicos (inclusive recursos naturais); da ascensão da lógica de livre mercado para conduzir os espaços públicos e privados. 
2. Expressão criada pelos autores visando consubstanciar, em sentido amplo, as concepçóes sobre a sociedade de Bauman $(2001 ; 2007 ; 2009 ; 2011)$ e Castells (1999), i.e., a liquidez e a organização em rede, respectivamente.

3. Como registram os próprios autores, o termo "academic capitalism" já havia sido utilizado por Hackett (1990) para sumarizar importantes mudanças estruturais no campo acadêmico (SLAUGHTER; LESLIE, 1997, p. 8).

\section{Referências}

ARRUDA, R. Notas sobre o conceito de indivíduo na teoria social contemporânea: um percurso a partir das obras de Stuart Hall, Norbert Elias, Richard Sennet e Zygmunt Bauman. Revista Aurora, Marília, v. 3, n. 2, p. 71-78, 2010.

BALL, S. Profissionalismo, gerencialismo e performatividade. Cadernos de Pesquisa, São Paulo, v. 35, n. 126, p. 539-564, 2005. http://dx.doi.org/10.1590/S0100-1574 $\underline{2005000300002}$

BANCO MUNDIAL. Higher education: the lessons of experience. Washington, D.C.: The World Bank Group, 1994.

BAUMAN, Z. 44 cartas do mundo líquido moderno. Rio de Janeiro: Zahar, 2011. . Modernidade líquida. Rio de Janeiro: Zahar, 2001. . Tempos líquidos. Rio de Janeiro: Zahar, 2007. - Vida líquida. 2. ed. Rio de Janeiro: Zahar, 2009.

BOLTANSKI, L.; CHIAPELlO, E. O Novo Espírito do Capitalismo. São Paulo: Martins Fontes, 2009.

BORGES, H. Conheça os bilionários convidados a "reformar" a educação brasileira de acordo com sua ideologia. The Intercept Brasil, nov. 2016. Disponível em: <https:// theintercept.com/2016/11/04/conheca-os-bilionarios-convidados-para-reformar-aeducacao-brasileira-de-acordo-com-sua-ideologia/>. Acesso em: 21 abr. 2017.

CANTWELL, B. Laboratory management, academic production, and the building blocks of academic capitalism. Higher Education, Dordrecht, v. 70, n. 3, p. 487-502, 2015. https://doi.org/10.1007/s10734-014-9851-9

CANTWELL, B.; KAUPPINEN, I. Academic Capitalism in Theory and Research. In: CANTWELL, B.; KAUPPINEN, I. (Orgs.). Academic capitalism in the age of globalization. Baltimore: John Hopkins University Press, 2014. p. 3-9.

CARABALLO, M.P.R. Significado del trabajo y sentido de la profesión en la academia en Colombia. Athenea Digital, Cerdanyola del Vallès, v. 16, n. 2, p. 427-435, 2016. https:// doi.org/10.5565/rev/athenea. 1799

CARVALHO, H.A. A mercantilização da educação superior brasileira e as estratégias de mercado das instituições lucrativas. Revista Brasileira de Educação, Rio de Janeiro, v. 18, n. 54, p. 761-776, 2013. http://dx.doi.org/10.1590/S1413-24782013000300013. 
CASADEI, E.B. Muito além do líquido: Modernidade, ideologia e cultura na obra de Zygmunt Bauman. Espaço Acadêmico, Maringá, n. 102, p. 81-88, 2009.

CASTELlS, M. A Sociedade em Rede. 8. ed. São Paulo: Paz e Terra, 1999.

CATANI, A.M.; OLIVEIRA, J.F. A reestruturação da educação superior no debate internacional: a padronização das políticas de diversificação e diferenciação. Revista Portuguesa de Educação, Braga, v. 13, n. 2, p. 29-52, 2000.

CATANI, A.M.; OLIVEIRA, J.F. As políticas de educação superior no PNE 2001. ProPosições, Campinas, v. 14, n. 1, p. 143-148, 2003.

CHAUÍ, M.S. A Universidade Operacional. Folha de S. Paulo, mar. 1999. Disponível em: swww.cacos.ufpr.br/obras/Marilena Chaui Universidade Operacional.doc $>$. Acesso em: 21 abr. 2017.

A universidade pública sob nova perspectiva. Revista Brasileira de Educação, Rio de Janeiro, n. 24, p. 5-15, 2003. http://dx.doi.org/10.1590/S1413-24782003000300002

. Contra a universidade operacional [aula magna]. São Paulo: Associação dos Docentes da USP, Faculdade de Arquitetura e Urbanismo, 8 ago. 2014. 174 min. Disponível em: <http://www.adusp.org.br/files/database/2014/tex chaui.pdf $>$. Acesso em: 21 abr. 2017.

. Contra a universidade operacional e a servidão voluntária [palestra de abertura]. Bahia: Universidade Federal da Bahia, 14 jul. 2016. Disponível em: <http://www. congresso.ufba.br/?p=1658>. Acesso em: 21 abr. 2017.

Escritos sobre a universidade. São Paulo: Editora UNESP, 2001.

CLARK, B. Creating Entrepreneurial Universities: Organizational Pathways of Transformation. Nova York: Emerald Group, 1998.

COLLYER, F. The production of scholarly knowledge in the global market arena: University ranking systems, prestige and power. Critical Studies in Education, Londres, v. 54, n. 3, p. 245-259, 2013. https://doi.org/10.1080/17508487.2013.788049

CUNHA, L.A. O desenvolvimento meandroso da educação brasileira entre o Estado e o mercado. Educação \& Sociedade, Campinas, v. 28, n. 100, p. 809-829, 2007. http:// dx.doi.org/10.1590/S0101-73302007000300009

DIAS, R.; SERAFIM, M. Comentários sobre as transformaçóes recentes na universidade pública brasileira. Avaliação, Campinas, v. 20, n. 2, 2015. http://dx.doi.org/10.590/ $\underline{\text { S1414-40772015000200004 }}$

DIAS SOBRINHO, J. Avaliação e transformações da educação superior brasileira (19952009): do provão ao SINAES. Avaliação, Campinas, v. 15, n. 1, 2010. http://dx.doi.org/ $\underline{10.1590 / S 1414-40772010000100011}$

Universidade e novos modos de produção, circulação e aplicação do conhecimento. Avaliação, Campinas, v. 19, n. 3, 2014. http://dx.doi.org/10.1590/S1414$\underline{40772014000300007}$

- Universidade fraturada: reflexôes sobre conhecimento e responsabilidade social. Avaliação, Campinas, v. 20, n. 3,2015. 
GRÜN, R. A promessa da "inserção profissional instigante" da sociedade em rede: a imposição de sentido e a sua sociologia. Dados, Rio de Janeiro, v. 46, n. 1, p. 5-37, 2003. http://dx.doi.org/10.1590/S0011-52582003000100001

HACKETT, E. J. Science as a vocation in the 1990s: the changing organizational culture of academic science. The Journal of Higher Education, v. 61, n. 3, p. 241-279, 1990. https:// doi.org/10.1080/00221546.1990.11780710

HAN, J.; HESHMATI, A. Determinants of financial rewards from industry-university collaborationinSouthKorea.InternationalJournalofEntrepreneurshipandInnovationManagement, Olney, v. 20, n. 3-4, p. 235-257, 2016. https://doi.org/10.1504/I]EIM.2016.077963

HERMANOWICZ, J. The Proliferation of Publishing: Economic Rationality and Ritualized Productivity in a Neoliberal Era. The American Sociologist, Dordrecht, v. 47, n. 2-3, p. 174-191, 2016a. https://doi.org/10.1007/s12108-015-9285-6

. Universities, Academic Careers, and the Valorization of "Shiny Things". In: BERMAN, E.P.; PARADEISE, C. (Orgs.). Research in the Sociology of Organizations. Bingley: Emerald Group, 2016b. v. 46. p. 303-328.

INSTITUTO NACIONAL DE ESTUDOS E PESQUISAS EDUCACIONAIS ANÍSIO TEIXEIRA(INEP).SinopseEstatísticadaEducaçãoSuperior2015.INEP,out.2016.Disponívelem: <http://portal.inep.gov.br/sinopses-estatisticas-da-educacao-superior $>$. Acesso em: 21 abr. 2017.

JESSOP, B. On academic capitalism. Critical Policy Studies, Londres, v. 12, n. 1, p. 104109, 2018. https://doi.org/10.1080/19460171.2017.1403342

Varieties of academic capitalism and entrepreneurial universities: On past research and three thought experiments. Higher Education, Dordrecht, v. 73, n. 6, p. 853870, 2017. https://doi.org/10.1007/s10734-017-0120-6

JOHNSON, A.T.; HIRT, J. Reshaping academic capitalism to meet development priorities: The case of public universities in Kenya. Higher Education, Dordrecht, v. 61, n. 4, p. 483-499, 2011. https://doi.org/10.1007/s10734-010-9342-6

KAIDESOJA, T.; KAUPPINEN, I. How to explain Academic Capitalism: a mechanismbased approach. In: CANTWELL, B.; KAUPPINEN, I. (Orgs.). Academic Capitalism in the age of globalization. Baltimore: John Hopkins University Press, 2014. p. 166-186.

KIRSCHBAUM, C. As redes introrganizacionais são inclusivas? Utopia e testes. Organizaçōes \& Sociedade, Salvador, v. 22, n. 74, p. 367-384, 2015. http://dx.doi. org/10.1590/1984-9230744

LÉDA, D.B.; MANCEBO, D. REUNI: heteronomia e precarização da universidade e do trabalho docente. Educação \& Realidade, Porto Alegre, v. 34, n. 1, p. 49-64, 2009.

LEHER, R. O BIRD e as reformas neoliberais na educação. PUC Viva, São Paulo, v. 1, n. 5, p. 16-22, 1999.

Reitor da UFRJ: PEC 241 trará o fim da gratuidade das universidades públicas. Conexão UFRJ, 2016. Disponível em: <https://www.brasil247.com/pt/247/ rio247/260599/Reitor-da-UFRJ-PEC-241-trar\%C3\%A1-o-fim-da-gratuidade-dasuniversidades-p\%C3\%BAblicas.htm>. Acesso em: 21 abr. 2017. 
MANCEBO, D.; SILVA JR., J.R. Expansão da educação superior e a reforma da rede federal de educação profissional. Revista Educação em Questão, Natal, v. 51, n. 37, p. 7394, 2015. http://dx.doi.org/10.21680/1981-1802.2015v51n37ID7172

MARTINS, A.L.M. A marcha do "capitalismo universitário" no Brasil nos anos 1990. Avaliação, Campinas, v. 13, n. 3, p. 733-743, 2008. http://dx.doi.org/10.1590/S1414$\underline{40772008000300006}$

MARTINS, C.B. A reforma universitária de 1968 e a abertura para o ensino superior privado no Brasil. Educação \& Sociedade, Campinas, v. 30, n. 106, p. 15-35, 2009. http:// dx.doi.org/10.1590/S0101-73302009000100002

MCCLURE, K.R.; TEITELBAUM, K. Leading schools of education in the context of academic capitalism: Deans' responses to state policy changes. Policy Futures in Education, Londres, v. 14, n. 6, p. 793-809, 2016. https://doi.org/10.1177/1478210316653690

MELO, L.; SALOMÃO, K. Com compra da Estácio, Kroton se torna “inalcançável”. Exame, ago. 2016. Disponível em: <http://exame.abril.com.br/negocios/com-compra-daestacio-kroton-se-torna-inalcancavel/>. Acesso em: 21 abr. 2017.

MENDOZA, P.; KUNTZ, A.M.; BERGER, J.B. Bourdieu and academic capitalism: Faculty "habitus" in materials science and engineering. Journal of Higher Education, Columbus, v. 83, n. 4, p. 558-581, 2012. https://doi.org/10.1080/00221546.2012.11777257

METCALFE, A.S. Revisiting academic capitalism in Canada: No longer the exception. Journal of Higher Education, Columbus, v. 81, n. 4, p. 489-514, 2010. https://doi. org/10.1353/jhe.0.0098

MOK, K.H. Academic capitalisation in the new millennium: the marketisation and corporatisation of higher education in Hong Kong. Policy \& Politics, Chichester, v. 29, n. 3, p. 299-315, 2001. https://doi.org/10.1332/0305573012501369

MÜNCH, R.; BAIER, C. Institutional struggles for recognition in the academic field: The case of university departments in German chemistry. Minerva, Dordrecht, v. 50, n. 1, p. 97-126, 2012. https://doi.org/10.1007/s11024-012-9189-3

OLIVEIRA, D.C.; MEIRA, T.A.V. A construção de um novo “espírito" do capitalismo em uma sociedade em rede. Caderno Eletrônico de Ciências Sociais, Vitória, v. 1, n. 1, p. $140-$ 154, 2013. https://doi.org/10.24305/cadecs.v1i1.5971

PERONI, V.M.V. A gestão democrática da educação em tempos de parceria entre o público e o privado. Pro-Posiçóes, Campinas, v. 23, n. 2, p. 19-31, 2012. http://dx.doi. org/10.1590/S0103-73072012000200003

RIBEIRO, R.J. A universidade e a vida atual: Fellini não via filmes. 2. ed. São Paulo: Editora USP, 2014.

SIGAHI, T.F.A.C.; SALTORATO, P. Ligas de Mercado Financeiro: perfil, atuação, inspiraçóes e a corrida dos engenheiros de produção aos bancos. In: ENCONTRO NACIONAL DE ENGENHARIA DE PRODUÇÃO, 37., 2017, Joinville, SC. Anais... Joinville: ABEPRO, 2017. p. 1-25. https://doi.org/10.14488/enegep2017 tn stp $247 \quad 429 \quad 32743$ 
SCHULZE-CLEVEN, T.; OLSON, J.R. Worlds of higher education transformed: toward varieties of academic capitalism. Higher Education, Dordrecht, v. 73, n. 6, p. 813831, 2017. https://doi.org/10.1007/s10734-017-0123-3

SGUISSARDI, V. Modelo de expansão da educação superior no Brasil: predomínio privado/mercantil e desafios para a regulação e a formação universitária. Educação \& Sociedade, Campinas, v. 29, n. 105, p. 991-1022, 2008a. http://dx.doi.org/10.1590/ $\underline{\text { S0101-73302008000400004 }}$

. Regulação estatal e desafios da expansão mercantil da educação superior. Educação \& Sociedade, Campinas, v. 34, n. 124, p. 943-960, 2013. http://dx.doi.org/10.1590/ $\underline{\text { S0101-73302013000300015 }}$

Regulação estatal versus cultura de avaliação institucional? Avaliação, Campinas, v. 13, n. 3, 2008b. http://dx.doi.org/10.1590/S1414-40772008000300016

. Universidade pública estatal: entre o público e o privado/mercantil. Educação \& Sociedade, Campinas, v. 26, n. 90, p. 191-222, 2005. http://dx.doi.org/10.1590/S0101$\underline{73302005000100009}$

SHIBAYAMA, S. Conflict between entrepreneurship and open science, and the transition of scientific norms. The Journal of Technology Transfer, Nova York, v. 37, n. 4, p. 508531, 2012. https://ssrn.com/abstract=2287039

SILVA JR., J.R.; FERREIRA, L.R.; KATO, F.B.G. Trabalho do professor pesquisador diante da expansão da pós-graduação no Brasil pós-LDB. Revista Brasileira de Educação, Rio de Janeiro, v. 18, n. 53, 2013. http://dx.doi.org/10.1590/S1413-24782013000200011

SILVA JR., J.R.; KATO, F.B.G. A política de internacionalização da educação superior no Plano Nacional de Pós-Graduação (2011-2020). Revista Internacional de Educação Superior, Campinas, v. 2, n. 1, p. 138-171, 2016. https://doi.org/10.22348/riesup.v2i1.7543

SILVA JR., J.R.; PIMENTA, A.V. Capitalismo, trabalho e educação: o caso das instituiçóes federais de educação superior. Germinal: Marxismo e Educação em Debate, Salvador, v. 6, n. 2, p. 28-41, 2014. http://dx.doi.org/10.9771/gmed.v6i2.13086

SILVA JR., J.R.; SGUISSARDI, V. Universidade Pública Brasileira no Século XXI. Educação superior orientada para o mercado e intensificação do trabalho docente. Espacios en Blanco, Tandil, v. 23, n. 1, p. 119-156, 2013.

SLAUGHTER, S.; CANTWELL, B. Transatlantic moves to the market: The United States and the European Union. Higher Education, Dordrecht, v. 63, n. 5, p. 583-606, 2012. https://doi.org/10.1007/s10734-011-9460-9

SLAUGHTER, S.; LESLIE, L. Academic Capitalism: Politics, Policies and the Entrepreneurial University. Baltimore: The Johns Hopkins University Press, 1997.

SLAUGHTER, S.; LESLIE, L. Expanding and Elaborating the Concept of Academic Capitalism. Organization, Londres, v. 8, n. 2, p. 154-161, 2001. https://doi.org/10.1177/ $\underline{1350508401082003}$

SLAUGHTER, S.; RHOADES, G. Academic Capitalism and the New Economy: Markets, State, and Higher Education. Baltimore: John Hopkins University Press, 2004. 
STÖCKELOVÁ, T. Power at the Interfaces: The Contested Orderings of Academic Presents and Futures in a Social Science Department. Higher Education Policy, Londres, v. 27, n. 4, p. 435-451, 2014. https://doi.org/10.1057/hep.2014.20

SWEDBERG, R. Sociologia Econômica: Hoje e amanhã. Tempo Social, São Paulo, v. 16, n. 2, p. 7-34, 2004. http://dx.doi.org/10.1590/S0103-20702004000200001

WAIZBORT, L. Formação, especialização, diplomação: da universidade à instituição de ensino superior. Tempo Social, São Paulo, v. 27, n. 2, p. 45-74, 2015. http://dx.doi. org/10.1590/0103-2070201523

WATERMEYER, R. Issues in the articulation of "impact": the responses of UK academics to "impact" as a new measure of research assessment. Studies in Higher Education, Londres, v. 39, n. 2, p. 359-377, 2014. https://doi.org/10.1080/03075079.2012.709490

Recebido em 10 de novembro de 2017.

Aceito em 10 de junho de 2018. 